\title{
Multi-detector computed tomography angiographic evaluation of right ventricular outflow tract obstruction and other associated cardiovascular anomalies in tetralogy of Fallot patients
}

\author{
Rani Kunti R. Singh ${ }^{A, B, C, D, E, F}$, Neeraj Jain ${ }^{A, B, C, D, E, F}$, Sunil Kumar ${ }^{A, D, E}$, Naveen Garg ${ }^{A, D}$ \\ Sanjay Gandhi Postgraduate Institute of Medical Sciences, India
}

\section{Abstract}

Purpose: To evaluate various types of right ventricular outflow tract obstruction associated with tetralogy of Fallot (TOF) with emphasis on the abnormality of pulmonary arterial system and other associated cardiovascular anomalies using computed tomography (CT) angiography.

Material and methods: We retrospectively evaluated 184 consecutive previously diagnosed TOF patients who underwent CT angiography in our department.

Results: Infundibular with pulmonary valvular stenosis was the most common type of stenosis (47.28\%) found, followed by isolated infundibular stenosis (34.23\%). Isolated abnormality of both right and left pulmonary arteries was also noted. Right side aortic arch (23.91\%) was the most common associated abnormality followed by double superior vena cava $(9.78 \%)$.

Conclusions: TOF is associated with various types of right ventricular outflow tract obstruction ranging from infundibular narrowing to isolated narrowing of right or left pulmonary arteries and is also associated with various other congenital abnormalities of the cardiovascular system. CT angiography is an excellent imaging modality, which provides comprehensive analysis of various abnormalities associated with TOF.

Key words: tetralogy of Fallot, pulmonary artery, RVOT.

\section{Introduction}

Tetralogy of Fallot (TOF) is the most common cyanotic congenital heart disease (CHD) and accounts for approximately $3 \%$ to $7 \%$ of all CHD $[1,2]$. The four components of TOF are ventricular septal defect, overriding of the aorta, right ventricular outflow tract obstruction, and right ventricular hypertrophy [3]. Association of atrial septal defect (ASD) with TOF is called pentalogy of Fallot. TOF has also been reported to be associated with various other congenital abnormalities including right-sided aortic arch, double superior vena cava (SVC), patent ductus arteriosus (PDA), etc.

Echocardiography is usually the first line of investigation, but it is an operator-dependent modality and pro- vides suboptimal information of cardiac and extra-cardiac vascular anomalies, particularly of the pulmonary arterial system. Pre-operative evaluation of pulmonary artery anatomy is an essential requirement because timing, type of surgical management, and postoperative prognosis depends upon the severity of pulmonary artery stenosis. Catheter cardiac angiography is an invasive procedure and provides 2D images only. Simultaneous evaluation of systemic and pulmonary vasculature is also difficult.

CT angiography is an excellent modality having a high spatial and temporal resolution, which helps in better visualisation and characterisation of cardiac anatomy and associated vascular anomalies, and provides detailed and accurate information about pulmonary arteries.

Correspondence address:

Dr. Neeraj Jain, Sanjay Gandhi Postgraduate Institute of Medical Sciences, India, e-mail: neerajdmrd@gmail.com

Authors' contribution:

A Study design · B Data collection · C Statistical analysis · D Data interpretation · E Manuscript preparation · F Literature search · G Funds collection 
CT angiography is also useful in the evaluation of postoperative patients, such as evaluation of shunt patency and assessment of other postoperative complications.

The aim of this study is to evaluate various types of right ventricular outflow tract obstruction associated with TOF, with emphasis on the pulmonary arterial system, such as type, site, size, and length of pulmonary artery narrowing and other associated vascular anomalies in TOF patients, using CT angiography.

\section{Material and methods}

This is a retrospective study. A total of 184 consecutive previously diagnosed TOF patients, irrespective of their age, who came CT angiography in Department of Radiodiagnosis of Sanjay Gandhi Postgraduate Institute of Medical Sciences, Lucknow, from January 2016 to June 2018 were included in the analysis. Postoperative patients were excluded from the analysis. This analysis was done after getting approval from the Ethical Committee of the institute and a waiver of informed consent was also obtained.

Out of 184 patients 137 were male and 47 were female. 124 patients were in the age range of $0-10$ years, 37 patients were 11-20 years old, 14 patients were 21 -30 years old, eight patients were 31-40 years old, and one patient was in the 41-50-year-old age group.

Table 1. Various types of right ventricular outflow tract obstruction

\begin{tabular}{|l|c|c|}
\hline Type of stenosis & $n$ & $\%$ \\
\hline Pulmonary infundibular and valvular stenosis & 87 & 47.28 \\
\hline Isolated pulmonary infundibular stenosis & 63 & 34.23 \\
\hline Right ventricular outflow track obstruction & 9 & 4.89 \\
\hline $\begin{array}{l}\text { Pulmonary infundibular, subvalvular and valvular } \\
\text { stenosis }\end{array}$ & 6 & 3.26 \\
\hline $\begin{array}{l}\text { Pulmonary infundibular, valvular, and supravalvular } \\
\text { stenosis }\end{array}$ & 4 & 2.17 \\
\hline Isolated pulmonary valvular stenosis & 4 & 2.17 \\
\hline Pulmonary infundibular and subvalvular stenosis & 4 & 2.17 \\
\hline Isolated supravalvular stenosis & 1 & 0.54 \\
\hline No significant pulmonary narrowing & 6 & 3.26 \\
\hline
\end{tabular}

Table 2. Main pulmonary artery morphology

\begin{tabular}{|l|c|c|}
\hline Morphology & $n$ & $\%$ \\
\hline Hypoplastic MPA & 131 & 71.19 \\
\hline Adequate size MPA & 43 & 23.36 \\
\hline Atretic MPA & 8 & 4.34 \\
\hline $\begin{array}{l}\text { Hypoplastic MPA continue as right pulmonary } \\
\text { artery, bifurcation not visualised }\end{array}$ & 2 & 1.08 \\
\hline
\end{tabular}

MPA - main pulmonary artery
CT pulmonary angiography was performed on a 64-slice scanner. Most of the patients required mild sedation with ketamine $(0.5 \mathrm{ml} / \mathrm{kg})$ and midazolam $(1 \mathrm{mg} / \mathrm{kg})$. Nonionic contrast (iohexol $350 \mathrm{mg} \%$ ) was injected by the IV route through a peripheral vein; the dose of contrast given was $1.5 \mathrm{ml} / \mathrm{kg}$. A pressure injector was used to administer the contrast at a rate of 1-2 ml/sec. Real-time contrast bolus tracking was used, in which repetitive low-dose images were obtained every 1-3 seconds at the level of the pulmonary artery after the contrast injection. Diagnostic image acquisition was started manually as soon as the contrast was visualised in vascular structures of the mediastinum (pulmonary arteries or any other vascular structure in case of anomalous vessels). The second phase of image acquisition was done immediately after the completion of the first scan. The images acquired were of $3 \mathrm{~mm}$ thickness ( 0.6 collimation) with reconstruction done in $1 \mathrm{~mm}$ thickness.

The imaging data were analysed for the type, site, and severity of the pulmonary stenosis. Sizes of the pulmonary arteries and other associated vascular anomalies were also noted.

\section{Results}

A total of 184 TOF patients were included in the analysis, irrespective of their age and sex.

Infundibular with pulmonary valvular stenosis was the most common type of stenosis (47.28\%) found, followed by isolated infundibular stenosis (34.23\%). Other less common types were right ventricular outflow obstruction $(4.89 \%)$, pulmonary infundibular stenosis with subvalvular, valvular stenosis (3.26\%), infundibular stenosis with supra-valvular, valvular stenosis (2.17\%), infundibular with sub-valvular stenosis $(2.17 \%)$, pulmonary valvular stenosis (2.17\%), and isolated supra-valvular stenosis $(0.54 \%)$. The main pulmonary artery (MPA) was hypoplastic in $71.19 \%$ of cases, atretic in $4.34 \%$, and with adequate calibre in $23.36 \%$ of cases. In two cases MPA was hypoplastic with non-visualisation of bifurcation, and it was seen to continue in the right pulmonary artery (RPA) (Table 1 and 2).

Further isolated abnormalities of both right and left pulmonary arteries were also noted. Six patients had isolated dilated left pulmonary artery (LPA), three patients had isolated dilatation at origin with normal calibre at the hila, and one patient had isolated dilatation of LPA at the hila with normal proximal calibre. Isolated left pulmonary artery atresia was noted in three patients, and in one patient there was atresia of both right and left pulmonary arteries. In one patient there was complete atresia of right, left, and main pulmonary arteries with both right and left pulmonary arteries reconstituted at the hila by collaterals. Other less common abnormalities of LPA and RPA were isolated LPA stenosis at origin with normal calibre at the hila, isolated stenosis of LPA at the origin with 
hypoplasia at the hila, isolated focal stenosis at the origin with post-stenotic aneurysmal dilatation and isolated narrowing of RPA at the origin with post-stenotic dilatation (Table 3).

All patients were evaluated for other associated vascular anomalies. Right-sided aortic arch (23.91\%) was the most common associated abnormality followed by double SVC (9.78\%), in which case both superior vena cava were draining into the right atrium, the left SVC through the coronary sinus. However, other variations were also noted such as right SVC draining into the right atrium and left SVC draining into the left atrium, and the left SVC was hypoplastic and the right was draining into the right atrium. ASD (3.80\%) and patent ductus arteriosus (8.15\%). Other less common anomalies noticed were aortic diverticulum, MPA diverticulum, LPA diverticulum, double-outlet right ventricle, ductus diverticulum, double aortic arch, dextrocardia, patent foramen ovale, D-Transposition of great arteries, pulmonary venous drainage abnormality (right superior and middle pulmonary vein draining into right atrium through SVC), aberrant right subclavian artery, aberrant left subclavian artery, etc. (Table 4).

Out of 184 patients, $50.54 \%$ of patients had significantly large size ( $>2 \mathrm{~mm}$ ) major aortopulmonary collateral arteries (MAPCAs), 11.41\% had small MAPCAs, and no MAPCAs were visualised in $38.04 \%$ of patients. We did not find any significant correlation between the type of pulmonary artery stenosis and size of MAPCAs.

\section{Discussion}

TOF is one of the most common cyanotic congenital heart diseases, characterised by right ventricular outflow (RVOF) tract obstruction, ventricular septal defect (VSD), overriding of the aorta, and hypertrophied right ventricle [1-3] (Figure 1). Causes of RVOF tract obstruction are sub-valvular narrowing due to muscular hypertrophy of septum infundibulum, septum deviation, and hypoplastic or stenosed pulmonary valve of MPA or its branches. It varies in severity from mild to severe obstruction (Figures 2 and 3). Pulmonary atresia is the most severe form of RVOF obstruction.

Echocardiography, CT, MRI, and catheter angiography are the commonly utilised modalities for the diagnosis and follow-up of these patients.

Due to its high spatial and temporal resolution and the capability of providing high-quality $3 \mathrm{D}$ reconstructed images, multi-detector CT (MDCT) has become the primary modality for a large number of patients, predominantly for evaluation of the pulmonary artery and major aortopulmonary collateral arteries (MAPCA). Newer generation CT scanners with an increased number of detectors and dual-source CT can lead to shorter scan time, large anatomical coverage, persistent and better enhancement with a lesser dose of contrast media,
Table 3. Morphology of right and left pulmonary arteries

\begin{tabular}{|l|c|c|}
\hline Morphology of LPA and RPA & $n$ & $\%$ \\
\hline Isolated dilated LPA & 6 & $3.26 \%$ \\
\hline $\begin{array}{l}\text { Isolated LPA stenosis at its origin with normal size } \\
\text { at hilum }\end{array}$ & 4 & $2.17 \%$ \\
\hline Isolated atresia of LPA & 3 & $1.63 \%$ \\
\hline $\begin{array}{l}\text { Isolated dilatation of proximal part of LPA } \\
\text { with normal size at hilum }\end{array}$ & 3 & $1.63 \%$ \\
\hline Dilatation of LPA at hilum with normal size at origin & 1 & $0.54 \%$ \\
\hline $\begin{array}{l}\text { Isolated LPA stenosis at origin with hypoplastic distal } \\
\text { part at hilum }\end{array}$ & 1 & $0.54 \%$ \\
\hline $\begin{array}{l}\text { Isolated LPA stenosis at origin with post stenotic } \\
\text { dilation at hilum }\end{array}$ & 1 & $0.54 \%$ \\
\hline $\begin{array}{l}\text { Isolated focal narrowing of RPA with post stenotic } \\
\text { dilatation }\end{array}$ & 1 & $0.54 \%$ \\
\hline $\begin{array}{l}\text { Both right and left pulmonary artery formed } \\
\text { at hilum by collaterals }\end{array}$ & 1 & $0.54 \%$ \\
\hline Both RPA and LPA not seen & 1 & $0.54 \%$ \\
\hline
\end{tabular}

LPA - left pulmonary artery, RPA - right pulmonary artery

Table 4. Various associated cardiovascular abnormalities

\begin{tabular}{|l|c|c|}
\hline $\begin{array}{l}\text { Associated vascular and non-vascular } \\
\text { anomalies }\end{array}$ & $n$ & $\%$ \\
\hline Right-sided aortic arch & 44 & $23.91 \%$ \\
\hline Double SVC & 18 & $9.78 \%$ \\
\hline Patent ductus arteriosus & 15 & $8.15 \%$ \\
\hline Atrial septal defect & 7 & $3.80 \%$ \\
\hline Aberrant right subclavian artery & 6 & $3.26 \%$ \\
\hline Aortic diverticulum & 3 & $1.63 \%$ \\
\hline MPA diverticulum & 3 & $1.63 \%$ \\
\hline LPA diverticulum & 2 & $1.08 \%$ \\
\hline Double outlet right ventricle & 2 & $1.08 \%$ \\
\hline Ductus diverticulum & 2 & $1.08 \%$ \\
\hline $\begin{array}{l}\text { Aberrant left subclavian artery with right side } \\
\text { aortic arch }\end{array}$ & 2 & $1.08 \%$ \\
\hline D-transpositioning of great vessels & 1 & $0.54 \%$ \\
\hline D-malpositioning of great vessels & 1 & $0.54 \%$ \\
\hline Double aortic arch & 1 & $0.54 \%$ \\
\hline Dextrocardia & 1 & $0.54 \%$ \\
\hline Patent foramen oval & 1 & $0.54 \%$ \\
\hline Single left SVA draining into right atrium & 1 & $0.54 \%$ \\
\hline $\begin{array}{l}\text { Right superior and middle pulmonary vein } \\
\text { draining into right atrium via SVA }\end{array}$ & 1 & $0.54 \%$ \\
\hline Azygous fissure in right lung & 1 & $0.54 \%$ \\
\hline Two lobes in both lungs & 1 & $0.54 \%$ \\
\hline SUC-sor & \\
\hline
\end{tabular}

SVC - superior vena cava, MPA - main pulmonary artery 

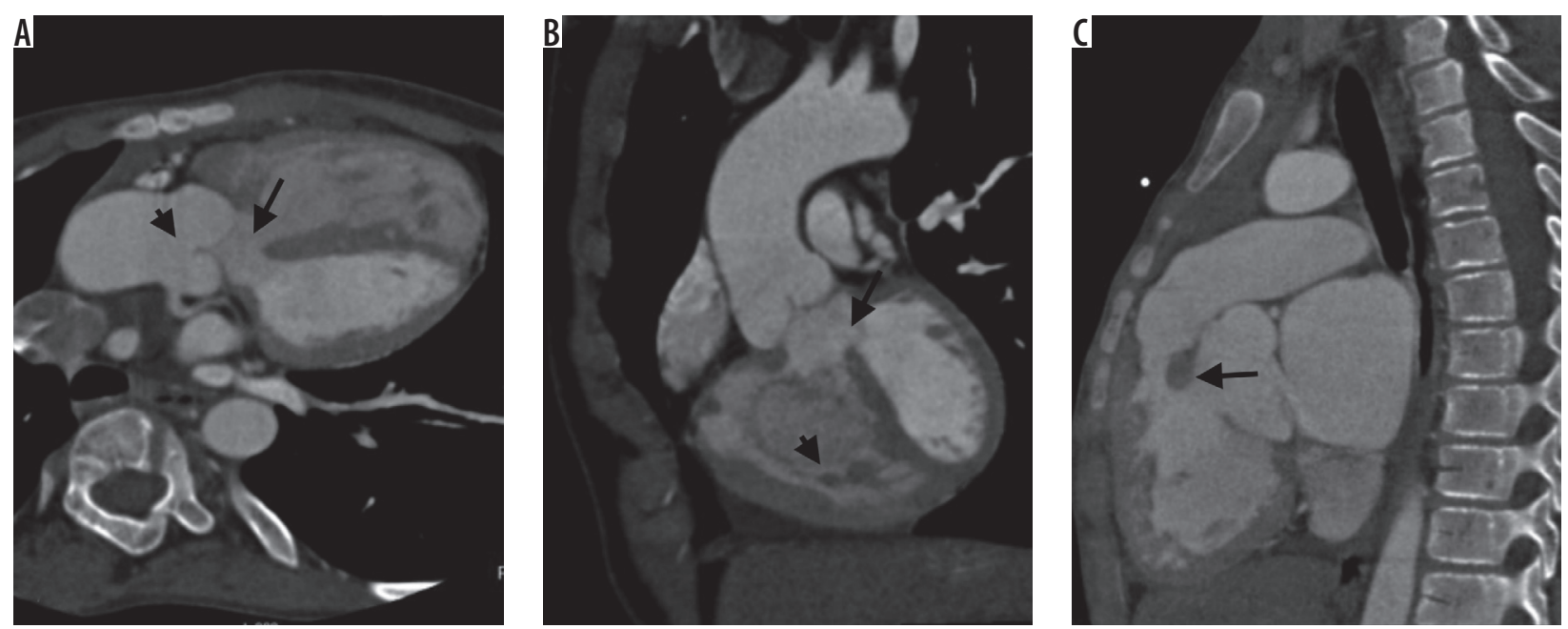

Figure 1. Typical computed tomography findings in tetralogy of Fallot's. Oblique axial image (A) shows ventricular septal defect (arrow) and overriding of aorta (B). Oblique coronal image (B) shows ventricular septal defect (arrow) with hypertrophied right ventricle. Sagittal image (C) shows infundibular narrowing
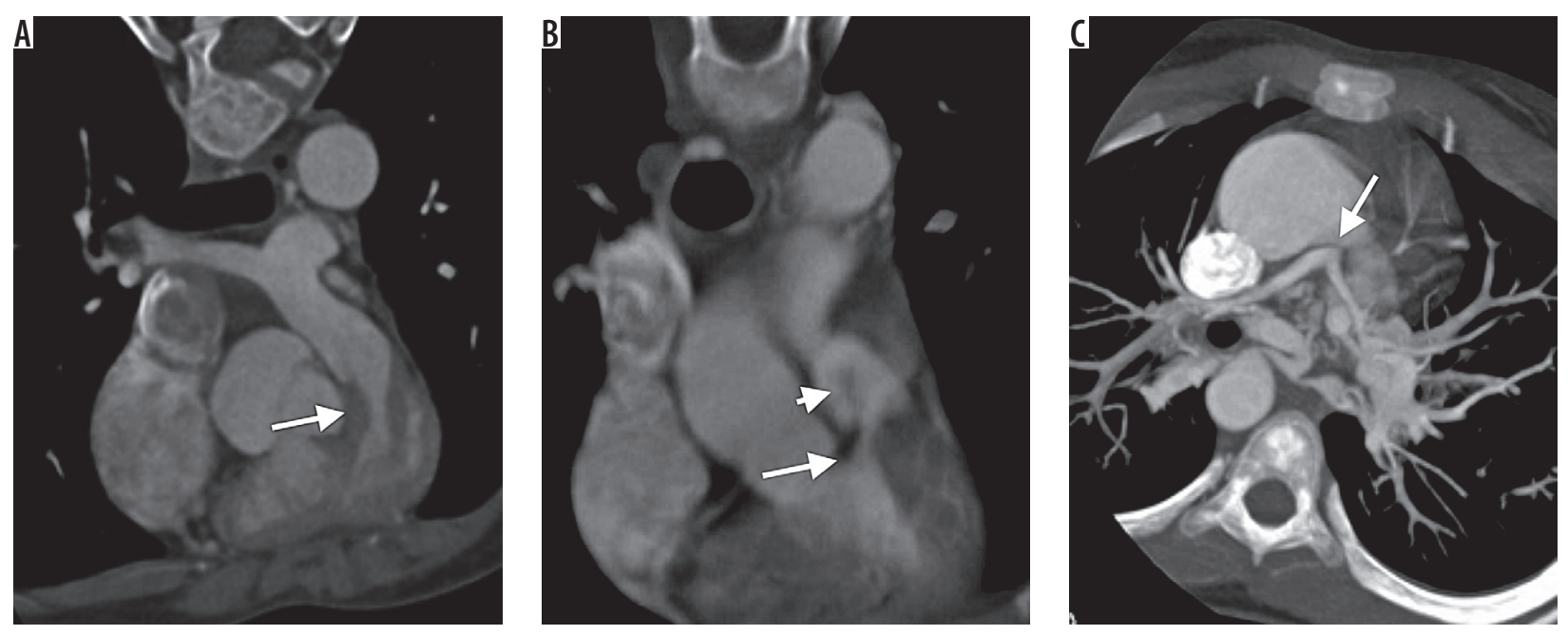

Figure 2. Computed tomography images showing different type of right ventricular outflow tract obstruction. A) Oblique coronal image showing infundibular narrowing. B) Oblique coronal image showing infundibular with valvular narrowing. C) Oblique axial showing atresia of main pulmonary artery (arrow) with hypoplastic right and left pulmonary arteries
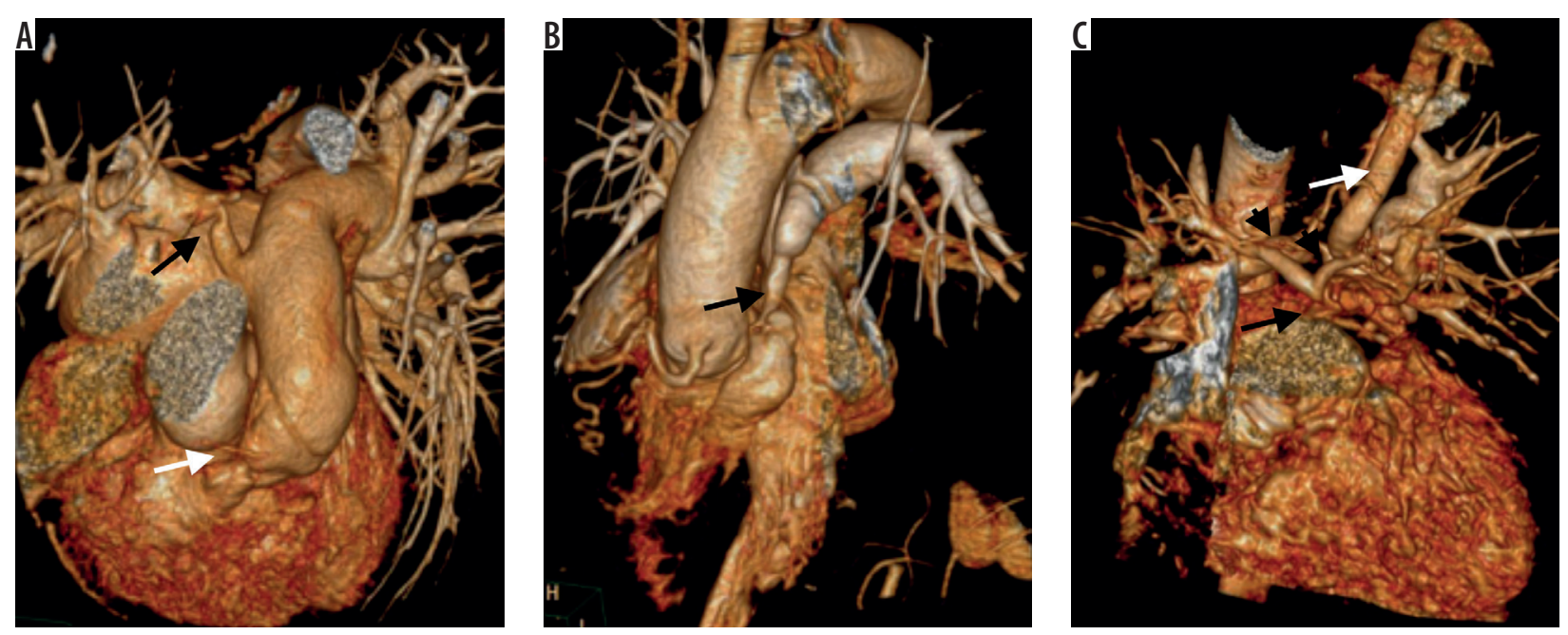

Figure 3. Volume rendered computed tomography images showing various types of pulmonary arterial narrowing in tetralogy of Fallot's. A) Infundibular narrowing (white arrow) and focal narrowing of right pulmonary (black arrow) with post stenotic dilatation. B) Narrowing of main pulmonary artery. C) Atretic main pulmonary artery (black arrow) with hypoplastic right and left pulmonary arteries (arrowheads) and a large major aorta-pulmonary collateral from left subclavian artery supplying left pulmonary artery 


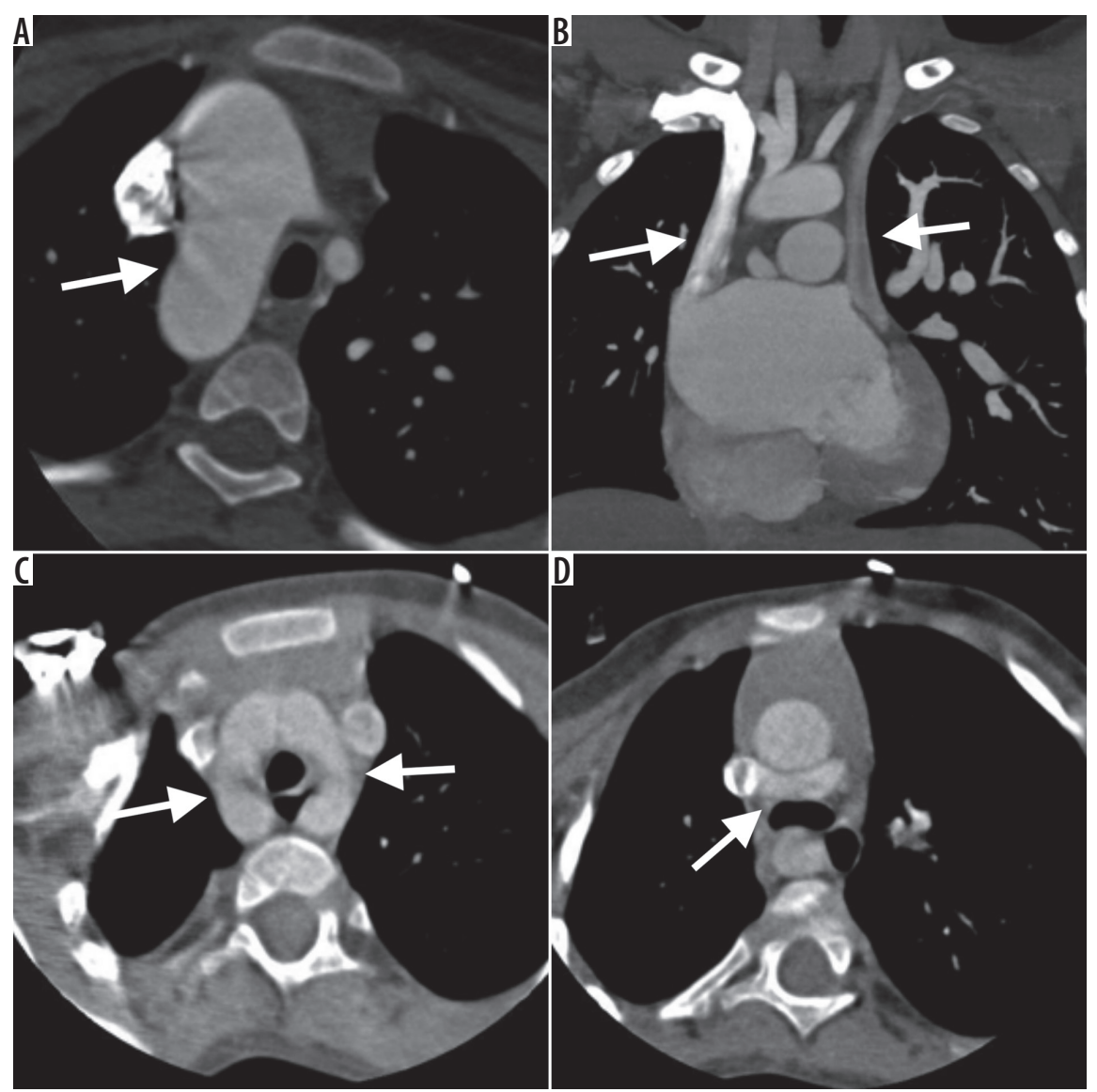

Figure 4. Computed tomography images showing various other congenital abnormalities associated with tetralogy of Fallot's. A) Axial image showing right sided aortic arch. B) Double superior vena cava. C) Double aortic arch. D) aberrant course of left brachiocephalic vein coursing posterior to ascending aorta

excellent quality of images, and has enabled better 3D reconstruction $[4,5]$. ECG gating further helps in motion-free evaluation of cardiac anatomy, pulmonary artery, great vessels, and pulmonary veins. Hence MDCT can provide a road map and invaluable information for further surgical management with detailed information of complex cardiac and extra-cardiac anatomy and airways. It can also serve as an excellent non-invasive method for the evaluation of shunt patently and other postoperative complications.

Detailed evaluation of the pulmonary arterial system and right ventricular outflow tract is a prerequisite for meticulous surgical planning, where CT angiography can provide invaluable information about presence, confluence, patency, and calibre of the central and peripheral pulmonary arteries [6,7]. Reformatted CT angiography images can show the exact site and degree of pulmonary artery stenosis (infundibular, valvular, sub-valvular, supra-valvular) accurately and non-invasively. CT angiography is sometimes also able to visualise the pulmonary arteries in cases of severe RVOF tract obstruction and pulmonary atresia in TOF patients $[7,8]$ when catheter angiography is difficult and not possible due to the small size of ostia.

MAPCA is another important aspect in the evaluation of TOF patients, where CT angiography provides accurate information about their number, size, site of origin, and course. MAPCAs are more common with hypoplastic or atretic pulmonary arteries and works as an alternative to systemic pulmonary artery supply. Most commonly MAPCAs arise from descending thoracic aorta but may arise from other major systemic arteries like subclavian arteries internal mammary arteries and branches of abdominal aorta etc. Precise visualization of MAPCAs is mandatory for optimal surgical planning. Large MAPCAs (> $2 \mathrm{~mm}$ ) must be occluded before the surgery to prevent an excessive return to the left heart when the aorta is cross-clamped on aorto-pulmonary bypass, which can lead to flooding of the operative field and can interfere with surgery [9-11]. In our study of 184 patients, 93 patients were found to have significantly large size MAPCAs measuring $>2 \mathrm{~mm}$. The largest size of MAPCA that we found measured $26.8 \mathrm{~mm}$ arising from the descending thoracic aorta. The common sites of origin of collaterals were descending thoracic aorta, arch of aorta, subclavian artery, brachiocephalic trunk, thyrocervical trunk, internal mammary arteries, inferior phrenic arteries, and carotid arteries.

Various studies have shown that infundibular stenosis is the most common cause of right ventricular outflow tract (RVOT) obstruction in TOF patients, and absent pulmonary valve is the least common [12]. In our study infundibular with valvular stenosis was the most com- 
mon type of RVOT obstruction (47.28\%) encountered, followed by isolated infundibular stenosis (34.23\%).

TOF is frequently associated with other congenital abnormalities of the cardiovascular system, such as right-sided aortic arch, double SVC, PDA, ASD, additional muscular ventricular septal defect, double aortic arch, dextrocardia, transposition of the great vessel, etc. (Figure 4). Right-sided aortic arch 23\% was the most common abnormality noted in this study, followed by double SVC $(9.8 \%)$.

In a small child, one should use the lowest radiation dose as is reasonably achievable. Various technical modifications can be done to reduce radiation, such as decreasing the tube current $[4,13,15]$ and potential $[4,14,16]$, increasing the pitch [15] and table speed [4,16], avoiding multi-phasic imaging [4], and minimising scan coverage. Rotational tube current modulation can be used to further lower radiation exposure [16-18]. The average radiation dose in this study was $5 \mathrm{mSv}$.

\section{Conclusions}

TOF is associated with various types of right ventricular outflow tract obstruction, ranging from infundibular narrowing to isolated narrowing of right or left pulmonary arteries, and also associated with various other congenital abnormalities of the cardiovascular system. CT angiography is an excellent imaging modality, which provides comprehensive analysis of various abnormalities associated with TOF.

\section{Disclosure}

The authors declare no conflicts of interest.

\section{References}

1. Garekar S, Humes R. Iap Speciality Series Pediatric Cardio. 2013. Cyanotic Congenital Heart Disease; p. 180.

2. Kemper AR, Mahle WT, Martin GR, et al. Strategies for implementing screening for critical congenital heart disease. Pediatrics 2011; 128: e1259-e1267.

3. Becker AE, Connor M, Anderson RH. Tetralogy of Fallot: amorphometric and geometric study. Am J Cardiol 1975; 35: 402-412.

4. Siegel MJ. Multiplanar and three-dimensional multi-detector row CT of thoracic vessels and airways in the pediatric population. Radiology 2003; 229: 641-650.

5. Spevak PJ, Johnson PT, Fishman EK. Surgically corrected congenital heart disease: utility of 64-MDCT. AJR Am J Roentgenol 2008; 191: 854-861.

6. Greil GF, Schoebinger M, Kuettner A, et al. Imaging of aortopulmonary collateral arteries with high-resolution multidetector CT. Pediatr Radiol 2006; 36: 502-509.

7. Hernandez RJ, Bank ER, Shaffer EM, Snider AR, Rosenthal A. Comparative evaluation of the pulmonary arteries in patients with right ventricular outflow tract obstructive lesions. AJR Am J Roentgenol 1987; 148: 1189-1194.

8. Taneja K, Sharma S, Kumar K, Rajani M. Comparison of computed tomography and cineangiography in the demonstration of central pulmonary arteries in cyanotic congenital heart disease. Cardiovasc Intervent Radiol 1996; 19: 97-100.

9. Sadiq N, Ullah M, Mahmoud A, et al. Perioperative major aortopulmonary collateral arteries (MAPCAS) coiling in tetralogy of Fallot patients undergoing for total correction. J Cardiol Curr Res 2015; 3: 00123
10. Zhang Y, Hua Z, Yang K, et al. Outcomes of the rehabilitative procedure for patients with pulmonary atresia, ventricular septal defect and hypoplastic pulmonary arteries beyond the infant period. Eur J Cardiothorac Surg 2014; 46: 297-303.

11. McElhinney DB, Reddy VM, Hanley FL. Tetralogy of Fallot with major aortopulmonary collaterals: early total repair. Pediatr Cardiol 1998; 19: 289-296.

12. Mohan A, Balat H, Vaghela D, et al. Study of role of MDCT in pulmonary angiography in evaluation of pulmonary arteries patterns in children with tetralogy of Fallot. Medicine 2013.

13. Tsai IC, Chen MC, Jan SL, et al. Neonatal cardiac multidetector row CT: why and how we do it. Pediatr Radiol 2008; 38: 438-451.

14. Leschka S, Oechslin E, Husmann L, et al. Pre- and postoperative evaluation of congenital heart disease in children and adults with 64-section CT. Radiographics 2007; 27: 829-846.

15. Haramati LB, Glickstein JS, Issenberg HJ, et al. MR imaging and CT of vascular anomalies and connections in patients with congenital heart disease: significance in surgical planning. Radiographics 2002; 22: 337-347.

16. Goo HW, Park IS, Ko JK, et al. CT of congenital heart disease: normal anatomy and typical pathologic conditions. Radiographics 2003; 23: S147-S165.

17. Goo HW, Suh DS. Tube current reduction in pediatric non-ECGgated heart CT by combined tube current modulation. Pediatr Radiol 2006; 36: 344-351.

18. Lerner CB, Frush DP, Boll DT. Evaluation of a coronary-cameral fistula: benefits of coronary dual-source MDCT angiography in children. Pediatr Radiol 2008; 38: 874-878. 